\title{
Theoretical Model Modified For Observed Data: Error Estimation Associated To Parameter
}

\author{
Dhritikesh Chakrabarty \\ Department of Statistics, Handique Girls' College, Guwahati-781001, Assam, India. \\ e-mail:dhritikesh.c@rediffmail.com,dhritikeshchakrabarty@gmail.com
}

\begin{abstract}
An attempt has been made in this paper to modify theoretical model in order to obtain one which is to be satisfied by the corresponding observed data containing error. The attempt has been made in the case of some commonly used theoretical models. Formula for error associated to the estimate of parameter has been derived since the estimate of parameter based on the observed data suffers from error. Also, one numerical application of the error in estimate has been shown in the case of a simple model.
\end{abstract}

Key Words: Error in observed data; model; parameter; error in estimate of parameter.

\section{Introduction}

Observed data collected from experiments or survey normally suffer from various errors. Error occurs due to cause/causes which is/are assignable (or intentional). Assignable cause/causes of error are controllable. Even if all the assignable causes of error are controlled or eliminated, the observed data still do not become free from error; they still suffer from some error which occurs due to some unknown and unintentional (chance) cause which is unavoidable, uncontrollable (Chakrabarty, 2014). If the variable(s) under study follow some rule/law that can be described by some theoretical model, the observed data on the variable(s) may not satisfy the same model due to the association of errors with the observed data on the variable(s). Consequently, findings obtained by analyzing the observations using this theoretical model also suffer from error. This leads to think of searching for the appropriate model to be satisfied by the observed data containing error corresponding to the theoretical model obeyed by the variable(s) under study. In this study, an attempt has been made to 
search for the appropriate model (models), corresponding to some important and widely used theoretical model(s) (Chakrabarty, 2014), that are satisfied by the observed data containing error. An attempt has also been made to search for the formula for error involved in the estimate(s) of parameter(s) in such situation. Also, one numerical application of the error in estimate has been shown in the case of a simple model $\{$ Chakrabarty $(2014,2015)\}$.

\section{Some Commonly Used Theoretical Models}

\section{Model-1}

In some situations, observation consists of a parameter and chance error.

If $X_{1}, X_{2}, \ldots \ldots \ldots \ldots, X_{n}$ are $n$ observations containing a parameter $\mu$ and chance error $\varepsilon_{i}$, then the observations satisfy the model

$$
X_{i}=\mu+\varepsilon_{i} \quad, \quad(i=1,2, \ldots \ldots \ldots, n)
$$

Had there been no chance error, $X_{i}$ would have been equal to $\mu$.

Thus $T\left(X_{i}\right)$, the errorless part of $X_{i}$ (in other words the true part of $X_{i}$ ) is nothing but $\mu$ i.e.

$$
\mu=T\left(X_{i}\right) \quad, \quad(i=1,2, \ldots \ldots \ldots, n)
$$

Thus the neither the observed values nor the mean of them can be the true value of the parameter $\mu$.

\section{Model-2}

Two variables $X$ and $Y$ are connected by the theoretical relationship

$$
f(X)=\mu \cdot f(Y)
$$

where (i) $f($.$) is some function$

and (ii) $\mu$ is the parameter.

Let

$$
Y_{1}, Y_{2}, \ldots \ldots \ldots \ldots, Y_{n}
$$

be the observations on $Y$ corresponding to the observations

$$
X_{1}, X_{2}, \ldots \ldots \ldots, X_{n}
$$

on $X$ respectively.

In this case, each observation is influenced by chance error.

Thus the observations satisfy the model

$$
X_{i}=T\left(X_{i}\right)+\varepsilon\left(X_{i}\right)
$$




$$
\& Y_{i}=T\left(Y_{i}\right)+\varepsilon\left(Y_{i}\right)
$$

where (i) $T\left(X_{i}\right)$ is the errorless/true part of $X_{i}$,

(ii) $\varepsilon\left(X_{i}\right)$ is the error associated to $X_{i}$,

(iii) $T\left(Y_{i}\right)$ is the errorless/true part of $Y_{i}$

\& (iv) $\varepsilon\left(Y_{i}\right)$ is the error associated to $Y_{i}$.

The theoretical relationship between $X$ and $Y$ is satisfied by the true part of observation $\left(X_{i}, Y_{i}\right)$ but not by the observation $\left(X_{i}, Y_{i}\right)$ itself.

Thus,

$$
f\left\{T\left(X_{i}\right)\right\}=\mu \cdot f\left\{T\left(Y_{i}\right)\right\}
$$

which means,

$$
\begin{gathered}
f\left\{Y_{i}-\varepsilon\left(Y_{i}\right)\right\}=\mu . f\left\{X_{i}-\varepsilon\left(X_{i}\right)\right\}, \\
(i=1,2, \ldots \ldots \ldots, n) .
\end{gathered}
$$

This is the model satisfied by the observations containing errors if the associated variables obey the theoretical model described by equation (2.3).

Moreover,

$$
\mu=f\left\{T\left(X_{i}\right)\right\} / f\left\{T\left(Y_{i}\right)\right\}=f\left\{X_{i}-\varepsilon\left(X_{i}\right)\right\} / f\left\{Y_{i}-\varepsilon\left(Y_{i}\right)\right\}
$$

Thus, the ratios

$$
f\left\{T\left(X_{i}\right)\right\} / f\left\{T\left(Y_{i}\right)\right\}, \quad(i=1,2, \ldots \ldots \ldots, n)
$$

or is equivalently the ratios

$$
f\left\{X_{i}-\varepsilon\left(X_{i}\right)\right\} / f\left\{Y_{i}-\varepsilon\left(Y_{i}\right)\right\} \quad, \quad(i=1,2, \ldots \ldots \ldots, n)
$$

are equal and their common value is nothing but the true value of the parameter $\mu$.

However, the values of these ratios are unknown.

On the other hand, neither the observed ratios

$$
f\left(X_{i}\right) / f\left(Y_{i}\right) \quad, \quad(i=1,2, \ldots \ldots \ldots, n)
$$

nor the mean of these observed ratios, whose values are known, can be the true value of the parameter $\mu$.

\section{Model-3}

The two variables $X$ and $Y$ are connected by the theoretical relationship

$$
f(X)=\mu \cdot g(Y)
$$

where (i) $f() \& g.($.$) are some functions$

and (ii) $\mu$ is the parameter.

In this case,

$$
f\left\{T\left(X_{i}\right)\right\}=\mu . g\left\{T\left(Y_{i}\right)\right\}
$$


which means,

$$
\begin{gathered}
f\left\{X_{i}-\varepsilon\left(X_{i}\right)\right\}=\mu . g\left\{Y_{i}-\varepsilon\left(Y_{i}\right)\right\}, \\
(i=1,2, \ldots \ldots \ldots, n) .
\end{gathered}
$$

This is the model satisfied by the observations containing errors if the associated variables obey the theoretical model described by equation (2.8).

Moreover,

$$
\mu=f\left\{T\left(X_{i}\right)\right\} / g\left\{T\left(Y_{i}\right)\right\}=f\left\{X_{i}-\varepsilon\left(X_{i}\right)\right\} / g\left\{Y_{i}-\varepsilon\left(Y_{i}\right)\right\}
$$

Thus, the ratios

$$
f\left\{T\left(X_{i}\right)\right\} / g\left\{T\left(Y_{i}\right)\right\}, \quad(i=1,2, \ldots \ldots \ldots, n)
$$

or is equivalently the ratios

$$
f\left\{X_{i}-\varepsilon\left(X_{i}\right)\right\} / g\left\{Y_{i}-\varepsilon\left(Y_{i}\right)\right\} \quad, \quad(i=1,2, \ldots \ldots \ldots, n)
$$

are equal and their common value is nothing but the true value of the parameter $\mu$.

However, the values of these ratios are unknown.

On the other hand, neither the observed ratios

$$
f\left(X_{i}\right) / g\left(Y_{i}\right) \quad, \quad(i=1,2, \ldots \ldots \ldots, n)
$$

nor the mean of these observed ratios, whose values are known, can be the true value of the parameter $\mu$.

\section{Model-4}

The variable $X$ is proportional to the variable $Y$ i.e. $X$ and $Y$ are connected by the theoretical relationship

$$
X=\mu . Y
$$

where $\mu$ is the parameter (the constant of proportionality).

In this case,

$$
T\left(X_{i}\right)=\mu . T\left(Y_{i}\right)
$$

which means,

$$
\begin{gathered}
\left\{X_{i}-\varepsilon\left(X_{i}\right)\right\}=\mu .\left\{Y_{i}-\varepsilon\left(Y_{i}\right)\right\}, \\
(i=1,2, \ldots \ldots \ldots, n) .
\end{gathered}
$$

This is the model satisfied by the observations containing errors if the associated variables obey the theoretical model described by equation (2.11).

Moreover,

$$
\mu=T\left(X_{i}\right) / T\left(Y_{i}\right)=\left\{X_{i}-\varepsilon\left(X_{i}\right)\right\} /\left\{Y_{i}-\varepsilon\left(Y_{i}\right)\right\}
$$

Thus, the ratios 


$$
T\left(X_{i}\right) / T\left(Y_{i}\right) \quad, \quad(i=1,2, \ldots \ldots \ldots, n)
$$

or is equivalently the ratios

$$
\left\{X_{i}-\varepsilon\left(X_{i}\right)\right\} /\left\{Y_{i}-\varepsilon\left(Y_{i}\right)\right\}, \quad(i=1,2, \ldots \ldots \ldots, n)
$$

are equal and this common value is nothing but the true value of the parameter $\mu$.

However, the values of these ratios are unknown.

On the other hand, neither the observed ratios

$$
X_{i} / Y_{i} \quad, \quad(i=1,2, \ldots \ldots \ldots, n)
$$

nor the mean of these observed ratios, whose values are known can be the true value of the parameter $\mu$.

\section{Model-5}

The variable $X$ is inversely proportional to the variable $Y$ i.e. $X$ and $Y$ are connected by the theoretical relationship

$$
X=\mu \cdot Y^{-1} \text { or } X . Y=\mu
$$

where $\mu$ is the parameter (the constant of proportionality).

In this case,

$$
T\left(X_{i}\right)=\mu \cdot\left\{T\left(Y_{i}\right)\right\}^{-1} \text { or } T\left(X_{i}\right) \cdot T\left(Y_{i}\right)=\mu
$$

which means,

$$
\begin{aligned}
\left\{X_{i}-\varepsilon\left(X_{i}\right)\right\}= & \mu .\left\{Y_{i}-\varepsilon\left(Y_{i}\right)\right\}^{-1} \text { or }\left\{X_{i}-\varepsilon\left(X_{i}\right)\right\} .\left\{Y_{i}-\varepsilon\left(Y_{i}\right)\right\}=\mu, \\
& (i=1,2, \ldots \ldots \ldots, n) .
\end{aligned}
$$

This is the model satisfied by the observations containing errors if the associated variables obey the theoretical model described by equation (2.14).

Moreover,

$$
\mu=T\left(X_{i}\right) . T\left(Y_{i}\right)=\left\{X_{i}-\varepsilon\left(X_{i}\right)\right\} .\left\{Y_{i}-\varepsilon\left(Y_{i}\right)\right\}
$$

Thus, the products

$$
T\left(X_{i}\right) . T\left(Y_{i}\right) \quad, \quad(i=1,2, \ldots \ldots \ldots, n)
$$

or is equivalently the products

$$
\left\{X_{i}-\varepsilon\left(X_{i}\right)\right\} .\left\{Y_{i}-\varepsilon\left(Y_{i}\right)\right\} \quad, \quad(i=1,2, \ldots \ldots \ldots, n)
$$

are equal and this common value is nothing but the true value of the parameter $\mu$.

However, the values of these products are unknown.

On the other hand, neither the observed products

$$
X_{i} . Y_{i}, \quad(i=1,2, \ldots \ldots \ldots \ldots, n)
$$


nor the mean of these observed products, whose values are known can be the true value of the parameter $\mu$.

\section{Model-6}

The variable $X$ is proportional to the square of the variable $Y$ i.e. $X$ and $Y$ are connected by the theoretical relationship

$$
X=\mu \cdot Y^{2}
$$

where $\mu$ is the parameter (the constant of proportionality).

In this case,

$$
T\left(X_{i}\right)=\mu .\left\{T\left(Y_{i}\right)\right\}^{2}
$$

which means,

$$
\begin{gathered}
\left\{X_{i}-\varepsilon\left(X_{i}\right)\right\}=\mu .\left\{Y_{i}-\varepsilon\left(Y_{i}\right)\right\}^{2}, \\
(i=1,2, \ldots \ldots \ldots, n) .
\end{gathered}
$$

This is the model satisfied by the observations containing errors if the associated variables obey the theoretical model described by equation (2.17).

Moreover,

$$
\mu=T\left(X_{i}\right) /\left\{T\left(Y_{i}\right)\right\}^{2}=\left\{X_{i}-\varepsilon\left(X_{i}\right)\right\} .\left\{Y_{i}-\varepsilon\left(Y_{i}\right)\right\}^{2}
$$

Thus, the ratios

$$
T\left(X_{i}\right) /\left\{T\left(Y_{i}\right)\right\}^{2},(i=1,2, \ldots \ldots \ldots, n)
$$

or is equivalently the ratios

$$
\left\{X_{i}-\varepsilon\left(X_{i}\right)\right\} /\left\{Y_{i}-\varepsilon\left(Y_{i}\right)\right\}^{2}, \quad(i=1,2, \ldots \ldots \ldots, n)
$$

are equal and this common value is nothing but the true value of the parameter $\mu$.

However, the values of these products are unknown.

On the other hand, neither the observed ratios

$$
X_{i} / Y_{i}^{2},(i=1,2, \ldots \ldots \ldots, n)
$$

nor the mean of these observed products, whose values are known can be the true value of the parameter $\mu$.

\section{Model-7}

The variable $X$ is inversely proportional to the square of the variable $Y$ i.e. $X$ and $Y$ are connected by the theoretical relationship

$$
X=\mu . Y^{-2} \text { or } X . Y^{2}=\mu
$$

where $\mu$ is the parameter (the constant of proportionality). 
In this case,

$$
T\left(X_{i}\right)=\mu .\left\{T\left(Y_{i}\right)\right\}^{-2} \text { or } T\left(X_{i}\right) .\left\{T\left(Y_{i}\right)\right\}^{2}=\mu
$$

which means,

$$
\begin{gathered}
\left\{X_{i}-\varepsilon\left(X_{i}\right)\right\}=\mu .\left\{Y_{i}-\varepsilon\left(Y_{i}\right)\right\}^{-2} \text { or }\left\{X_{i}-\varepsilon\left(X_{i}\right)\right\} .\left\{Y_{i}-\varepsilon\left(Y_{i}\right)\right\}^{2}=\mu, \\
(i=1,2, \ldots \ldots \ldots, n) .
\end{gathered}
$$

This is the model satisfied by the observations containing errors if the associated variables obey the theoretical model described by equation (2.20).

Moreover,

$$
\mu=T\left(X_{i}\right) \cdot\left\{T\left(Y_{i}\right)\right\}^{2}=\left\{X_{i}-\varepsilon\left(X_{i}\right)\right\} .\left\{Y_{i}-\varepsilon\left(Y_{i}\right)\right\}^{2}
$$

Thus, the products

$$
T\left(X_{i}\right) .\left\{T\left(Y_{i}\right)\right\}^{2},(i=1,2, \ldots \ldots \ldots, n)
$$

or is equivalently the products

$$
\left\{X_{i}-\varepsilon\left(X_{i}\right)\right\} .\left\{Y_{i}-\varepsilon\left(Y_{i}\right)\right\}^{2}, \quad(i=1,2, \ldots \ldots \ldots, n)
$$

are equal and this common value is nothing but the true value of the parameter $\mu$.

However, the values of these products are unknown.

On the other hand, neither the observed products

$$
X_{i} . Y_{i}^{2},(i=1,2, \ldots \ldots \ldots, n)
$$

nor the mean of these observed products, whose values are known can be the true value of the parameter $\mu$.

\section{Model-8}

The variable $Y$ theoretically depends linearly upon the variable $X$ i.e. $X$ and $Y$ are connected by the theoretical relationship

$$
Y=\alpha+\beta X
$$

where $\alpha \& \beta$ are parameters.

In this case, $T\left(X_{i}\right)$ and $T\left(Y_{i}\right)$ satisfy the theoretical relationship and thus

$$
T\left(Y_{i}\right)=\alpha+\beta . T\left(X_{i}\right)
$$

which implies

$$
Y_{i}=\alpha+\beta X_{i}+\left\{\varepsilon\left(Y_{i}\right)-\beta \varepsilon\left(X_{i}\right)\right\}
$$

Thus the observed values satisfy the model

$$
\begin{gathered}
Y_{i}=\alpha+\beta X_{i}+\xi_{i} \\
\text { where } \xi_{i}=\varepsilon\left(Y_{i}\right)-\beta \varepsilon\left(X_{i}\right), \\
(i=1,2, \ldots \ldots \ldots, n) .
\end{gathered}
$$


Here $\xi_{i}$, being a linear function of chance error variables, is also a chance error variable.

This is the model satisfied by the observations containing errors if the associated variables obey the theoretical model described by equation (2.23).

\section{Model-9}

The variable $Y$ theoretically depends linearly upon the variable $X$ i.e. $X$ and $Y$ are connected by the theoretical relationship

$$
Y=\alpha+\beta X+\gamma X^{2}
$$

where $\alpha, \beta \& \gamma$ are parameters.

In this case, $T\left(X_{i}\right)$ and $T\left(Y_{i}\right)$ satisfy the theoretical relationship and thus

$$
T\left(Y_{i}\right)=\alpha+\beta T\left(X_{i}\right)+\gamma \cdot\left\{T\left(X_{i}\right)\right\}^{2}
$$

which implies

$$
Y_{i}=\alpha+\beta X_{i}+\gamma X_{i}^{2}+\left\{\varepsilon\left(Y_{i}\right)-\beta \varepsilon\left(X_{i}\right)-2 \gamma X_{i} . \varepsilon\left(X_{i}\right)-\gamma \cdot \varepsilon\left(X_{i}\right)^{2}\right\}
$$

Thus the observed values satisfy the model

$$
\begin{gathered}
Y_{i}=\alpha+\beta X_{i}+\gamma X_{i}^{2}+\xi_{i} \\
\text { where } \quad \xi_{i}=\varepsilon\left(Y_{i}\right)-\beta \varepsilon\left(X_{i}\right)-2 \gamma X_{i} . \varepsilon\left(X_{i}\right)-\gamma \cdot \varepsilon\left(X_{i}\right)^{2}, \\
(i=1,2, \ldots \ldots \ldots, n) .
\end{gathered}
$$

Here $\xi_{i}$ being a linear function of chance error variables is also a chance error variable.

This is the model satisfied by the observations containing errors if the associated variables obey the theoretical model described by equation (2.26).

\section{Model-10}

The variable $Y$ theoretically depends exponentially upon the variable $X$ i.e. $X$ and $Y$ are connected by the theoretical relationship

$$
Y=\lambda \exp (-v X)
$$

where $\lambda$ and $v$ are parameters.

In this case, $T\left(X_{i}\right)$ and $T\left(Y_{i}\right)$ satisfy the theoretical relationship and thus

$$
T\left(Y_{i}\right)=\lambda \exp \left\{-v \cdot T\left(X_{i}\right)\right\}
$$

which implies

$$
Y_{i}=\varepsilon\left(Y_{i}\right)+\lambda \exp \left\{-v \cdot \varepsilon\left(X_{i}\right)\right\} \cdot \exp \left\{-v X_{i}\right\}
$$

Thus the observed values satisfy the model

$$
Y_{i}=\varepsilon\left(Y_{i}\right)+\xi_{i} \cdot \exp \left\{-v X_{i}\right\}
$$




$$
\begin{array}{ll}
\text { where } \quad & \xi_{i}=\lambda \exp \left\{-v . \varepsilon\left(X_{i}\right)\right\}, \\
& (i=1,2, \ldots \ldots \ldots, n) .
\end{array}
$$

Here $\xi_{i}$ being a exponential function of chance error variables is also a chance error variable.

This is the model satisfied by the observations containing errors if the associated variables obey the theoretical model described by equation (2.29).

\section{Model-11}

The variable $Y$ theoretically depends negatively exponentially upon the variable $X$ i.e. $X$ and $Y$ are connected by the theoretical relationship

$$
Y=\lambda \exp \left(-v X^{-1}\right)
$$

where $\lambda$ and $v$ are parameters.

In this case, $T\left(X_{i}\right)$ and $T\left(Y_{i}\right)$ satisfy the theoretical relationship and thus

which implies

$$
T\left(Y_{i}\right)=\lambda \exp \left[-v \cdot\left\{T\left(X_{i}\right)\right\}^{-1}\right]
$$

$$
\begin{gathered}
Y_{i}=\varepsilon\left(Y_{i}\right)+\lambda \exp \left[-v \cdot\left\{X_{i}-\varepsilon\left(X_{i}\right)\right\}^{-1}\right], \\
(i=1,2, \ldots \ldots \ldots, n) .
\end{gathered}
$$

This is the model satisfied by the observations containing errors if the associated variables obey the theoretical model described by equation (2.32).

\section{Model-12}

The variable $Y$ theoretically depends upon the variable $X$ by modified exponentially law i.e. $X$ and $Y$ are connected by the theoretical relationship

$$
Y=\mu+\lambda \exp (-v X)
$$

where $\mu, \lambda$ and $v$ are parameters.

In this case, $T\left(X_{i}\right)$ and $T\left(Y_{i}\right)$ satisfy the theoretical relationship and thus

$$
T\left(Y_{i}\right)=\mu+\lambda \exp \left\{-v T\left(X_{i}\right)\right\}
$$

which implies

$$
Y_{i}=\mu+\varepsilon\left(Y_{i}\right)+\lambda \exp \left[-v \cdot\left\{X_{i}-\varepsilon\left(X_{i}\right)\right\}\right]
$$

which further implies

$$
Y_{i}=\mu_{i}+\xi_{i} \cdot \exp \left\{-v X_{i}\right\}
$$

$$
\text { where } \begin{gathered}
\mu_{i}=\mu+\varepsilon\left(Y_{i}\right) \quad \& \xi_{i}=\lambda . \exp \left\{v . \varepsilon\left(X_{i}\right)\right\}, \\
(i=1,2, \ldots \ldots \ldots, n) .
\end{gathered}
$$

Here $\xi_{i}$ being a exponential function of chance error variables is also a chance error variable. 
This is the model satisfied by the observations containing errors if the associated variables obey the theoretical model described by equation (2.34).

\section{Model-13}

In Situation-12, it may be so that the variable $Y$ depends theoretically upon the variable $X$ by the relationship

$$
Y=\mu+\lambda \exp \left(-v X^{-1}\right)
$$

where $\mu, \lambda$ and $v$ are parameters.

In this case,

$$
T\left(Y_{i}\right)=\mu+\lambda \exp \left[-v \cdot\left\{T\left(X_{i}\right)\right\}^{-1}\right]
$$

which implies,

$$
\begin{gathered}
Y_{i}-\varepsilon\left(Y_{i}\right)=\mu+\lambda \exp \left[-v \cdot\left\{X_{i}-\varepsilon\left(X_{i}\right)\right\}^{-1}\right] \\
Y_{i}=\varepsilon\left(Y_{i}\right)+\mu+\lambda \exp \left[-v \cdot\left\{X_{i}-\varepsilon\left(X_{i}\right)\right\}^{-1}\right], \\
(i=1,2, \ldots \ldots \ldots, n) .
\end{gathered}
$$$$
\text { which further implies, }
$$

This is the model satisfied by the observations containing errors if the associated variables obey the theoretical model described by equation (2.36).

\section{Error involved in estimate of the parameter $\mu$ (in Model-1):}

If

$$
X_{1}, X_{2}, \ldots \ldots \ldots, X_{n}
$$

are $n$ observations containing a parameter $\mu$ and chance error $\varepsilon_{i}$, then the observations satisfy the model-1 described by

$$
X_{i}=\mu+\varepsilon_{i}, \quad(i=1,2, \ldots \ldots \ldots, n)
$$

Here,

$$
\mu=T\left(X_{i}\right) \quad, \quad(i=1,2, \ldots \ldots \ldots, n)
$$

The existing methods of estimation namely least squares method, maximum likelihood method, minimum variance unbiased method, method of moment and method of minimum chi-square \{Aldrich (1930), Anders (1999), Barnard (1949), Birnbaum (1962), Ivory (1825), Kendall \& Stuart (1977), Lehmann \& Casella George(1998), Lucien (1990), Walker \& Lev (1965)\} provides

$$
\bar{X}=n^{-1} \sum_{i=1}^{n} X_{i}
$$

as estimator of the parameter $\mu$.

This estimator suffers from an error 


$$
\overline{\varepsilon_{i}}=n^{-1} \sum_{i=1}^{n} \varepsilon_{i}
$$

which may not be zero Chakrabarty $(2014,2015)\}$.

This is the amount of error involved in the estimate of the parameter obtained by the existing statistical method of estimation.

\section{Some Example of Error (in case of Model-1)}

\section{Example-4.1}

Values of annual maximum Temperature at Guwahati observed during the period from 1969 to 2013 have been presented in Table-4.1.

\section{Table-4.1}

Observed Value of Annual Maximum of Ambient Air Temperature (in Degree Celsius) at Guwahati occurred during Temperature Periodic Year (TPY)

\begin{tabular}{|c|c|c|c|c|c|}
\hline $\begin{array}{l}\text { TPY } \\
\text { No }\end{array}$ & $\begin{array}{l}\text { Observed } \\
\text { Value }\end{array}$ & $\begin{array}{c}\text { Calendar Year, Month } \\
\& \text { Date } \\
\text { of occurrence }\end{array}$ & $\begin{array}{c}\text { TPY } \\
\text { No }\end{array}$ & $\begin{array}{c}\text { Observed } \\
\text { Value }\end{array}$ & $\begin{array}{c}\text { Calendar Year, Month } \\
\& \text { Date } \\
\text { of occurrence }\end{array}$ \\
\hline 1 & 37.1 & 1969, May, 20 & 23 & 37.4 & 1991, July, 20 \\
\hline 2 & 36.6 & 1970, April,01 & 24 & 39.4 & 1992, April, 16 \\
\hline 3 & 36.0 & 1971, March, 27 & 25 & 36.4 & 1993, September, 08 \\
\hline 4 & 35.7 & 1972, July, 14 & 26 & 38.1 & 1994, May, 07 \\
\hline 5 & 39.0 & 1973, April,10 & 27 & 36.3 & 1995, May, 14 \\
\hline 6 & 36.1 & 1974, August, 14 & 28 & 39.9 & 1996, April, 19 \\
\hline 7 & 39.2 & 1975, April, 10 & 29 & 37.4 & 1998, May 21 \\
\hline 8 & 39.0 & 1976, April,17 & 30 & 37.5 & 2000, May, 13 \\
\hline 9 & 35.3 & 1977, August, 14 & 31 & 36.7 & 2001, April,07 \\
\hline 10 & 36.8 & 1978, Мay, 19 & 32 & 35.5 & 2002, May, 17 \\
\hline 11 & 38.6 & 1979, March, 27 & 33 & 37.4 & 2003, July, 26 \\
\hline 12 & 35.1 & 1980, July, 01 & 34 & 38.0 & 2004, March, 28 \\
\hline 13 & 35.8 & 1981, June, 21 & 35 & 36.6 & 2005, July, 30 \\
\hline 14 & 36.5 & 1982, May, 26 & 36 & 38.0 & 2006, August, 11 \\
\hline 15 & 36.7 & 1983, April, 06 & 37 & 37.3 & 2007, Мay, 06 \\
\hline 16 & 37.2 & 1984, April, 06 & 38 & 37.3 & 2008, August, 08 \\
\hline 17 & 36.5 & 1985, April,26 & 39 & 38.0 & 2009, Мay, 23 \\
\hline 18 & 38.4 & 1986, April,03 & 40 & 37.2 & 2010, July, 03 \\
\hline 19 & 37.2 & 1987, May, 19 & 41 & 37.3 & 2011, August, 30 \\
\hline 20 & 36.4 & 1988, August, 03 & 42 & 37.4 & 2012, April,03 \\
\hline 21 & 36.7 & 1989, July, 23 & 43 & 38.8 & 2013, June, 12 \\
\hline 22 & 36.0 & 1990, September, 02 & & & \\
\hline
\end{tabular}


Observation on annual maximum temperature at a location satisfies the situation -1 \{ Chakrabarty $(2014,2015)\}$.

It has been found that the true value of the central tendency of annual maximum temperature at Guwahati is 37.25 Degree Celsius (Chakrabarty, 2015).

The estimated value of the central tendency computed from these observations by the existing statistical method of estimation i.e. by applying the formula given by equation (3.3) has been found to be 37.20465116 Degree Celsius.

Thus, the estimate of the central tendency suffers from an amount

$$
0.04534884 \text { Degree Celsius+ }
$$

of error.

This can be obtained by equation (3.3) from the amounts of errors involved in the observations as shown in the following table Table-4.2:

\section{Table-4.2}

Error associated to Observed Value of Annual Maximum of Ambient Air Temperature (in Degree Celsius) at Guwahati occurred during Temperature Periodic Year (TPY)

\begin{tabular}{|c|c|c|c|c|c|}
\hline $\begin{array}{c}\text { TPY } \\
\text { No }\end{array}$ & $\begin{array}{c}\text { Observed } \\
\text { Value }\end{array}$ & $\begin{array}{c}\text { Amount of Error Involved } \\
\text { = Observed Value }-37.25\end{array}$ & $\begin{array}{c}\text { TPY } \\
\text { No }\end{array}$ & $\begin{array}{c}\text { Observed } \\
\text { Value }\end{array}$ & $\begin{array}{c}\text { Amount of Error Involved }= \\
\text { Observed Value - 37.25 }\end{array}$ \\
\hline 1 & 37.1 & -0.15 & 23 & 37.4 & 0.15 \\
\hline 2 & 36.6 & -0.65 & 24 & 39.4 & -0.85 \\
\hline 3 & 36.0 & -1.25 & 25 & 36.4 & 0.85 \\
\hline 4 & 35.7 & -1.55 & 26 & 38.1 & -0.95 \\
\hline 5 & 39.0 & 1.75 & 27 & 36.3 & 0.15 \\
\hline 6 & 36.1 & -1.15 & 28 & 39.9 & 0.25 \\
\hline 7 & 39.2 & 1.95 .0 & 29 & 37.4 & -0.55 \\
\hline 8 & 39.0 & 1.75 & 30 & 37.5 & -1.75 \\
\hline 9 & 35.3 & -1.95 & 31 & 36.7 & 0.15 \\
\hline 10 & 36.8 & -0.45 & 32 & 35.5 & -0.65 \\
\hline 11 & 38.6 & 1.35 & 33 & 37.4 & 0.75 \\
\hline 12 & 35.1 & -2.15 & 34 & 38.0 & 0.05 \\
\hline 13 & 35.8 & -1.45 & 35 & 36.6 & 0.05 \\
\hline 14 & 36.5 & -0.45 & 36 & 38.0 & 0.75 \\
\hline 15 & 36.7 & -0.55 & 37 & 37.3 & -0.05 \\
\hline 16 & 37.2 & -0.05 & 38 & 37.3 & 0.05 \\
\hline 17 & 36.5 & -0.75 & 39 & 38.0 & 0.15 \\
\hline 18 & 38.4 & 1.15 & 40 & 37.2 & 1.55 \\
\hline 19 & 37.2 & -0.05 & 41 & 37.3 & \\
\hline 20 & 36.4 & -0.85 & 42 & 37.4 & \\
\hline 21 & 36.7 & -0.55 & 43 & 38.8 & \\
\hline 22 & 36.0 & -1.25 & & & \\
\hline & & & & & \\
\hline
\end{tabular}




\section{Example-4.2}

Values of annual minimum Temperature at Guwahati observed during the period from 1969 to 2013 have been presented in Table-4.3.

\section{Table-4.3}

Observed Value of Annual Minimum of Ambient Air Temperature (in Degree Celsius) at Guwahati occurred during Temperature Periodic Year (TPY)

\begin{tabular}{|c|c|c|c|c|c|}
\hline $\begin{array}{l}\text { TPY } \\
\text { No }\end{array}$ & $\begin{array}{l}\text { Observed } \\
\text { Value }\end{array}$ & $\begin{array}{l}\text { Calendar Year, } \\
\text { Month \& Date } \\
\text { of occurrence }\end{array}$ & $\begin{array}{l}\text { TPY } \\
\text { No }\end{array}$ & $\begin{array}{l}\text { Observed } \\
\text { Value }\end{array}$ & $\begin{array}{c}\text { Calendar Year, Month } \\
\& \text { Date } \\
\text { of occurrence }\end{array}$ \\
\hline 1 & 6.6 & 1969, January,16 & 23 & 7.4 & 1991, January, 20 \\
\hline 2 & 6.6 & 1969, December, 27 & 24 & 5.9 & 1992, January, 05 \\
\hline 3 & 5.9 & $\begin{array}{l}\text { 1971, January, } 31 \\
\text { \& February, } 01\end{array}$ & 25 & 8.4 & 1993, February, 23 \\
\hline 4 & 8.2 & 1972, January, 21 & 26 & 7.8 & 1993, December, 27 \\
\hline 5 & 5.0 & 1973, February, 03 & 27 & 7.5 & 1995, January, 22 \\
\hline 6 & 6.3 & 1974, February, 07 & 28 & 9.4 & 1996, January,19 \\
\hline 7 & 7.4 & 1975, January, 19 & 29 & NA & NA \\
\hline 8 & 6.6 & 1976, January, 22 & 30 & NA & NA \\
\hline 9 & 6.2 & 1977, January, 30 & 31 & NA & NA \\
\hline 10 & 7.3 & 1978, January, 12 & 32 & 8.9 & 2001, January, 08 \\
\hline 11 & 6.2 & 1979, January,09 & 33 & 8.6 & 2002, January, 26 \\
\hline 12 & 6.4 & 1980, February, 08 & 34 & 8.0 & 2003, January, 16 \\
\hline 13 & 7.5 & 1981, January,10 & 35 & 7.9 & 2004, February, 04 \\
\hline 14 & 8.3 & 1982, February, 07 & 36 & 6.7 & 2004, December, 27 \\
\hline 15 & 4.9 & 1983, January, 06 & 37 & 9.6 & 2006, January, 12 \\
\hline 16 & 6.1 & 1984, January, 30 & 38 & 6.4 & 2007, January, 18 \\
\hline 17 & 7.8 & 1985, January, 19 & 39 & 7.8 & 2008, February, 03 \\
\hline 18 & 8.6 & 1986, January, 20 & 40 & 9.9 & 2009, January, 07 \\
\hline 19 & 7.7 & 1987, January, 05 & 41 & 8.6 & 2010, January, 03 \\
\hline 20 & 9.2 & 1988, January, 01 & 42 & 7.0 & 2011, January, 21 \\
\hline 21 & 6.7 & 1989, January, 14 & 43 & 6.4 & 2012, January, 15 \\
\hline 22 & 8.6 & 1989, December, 31 & 44 & 5.6 & 2013, January, 11 \\
\hline
\end{tabular}

Observation on annual minimum temperature at a location satisfies the situation -1 \{ Chakrabarty $(2014,2015)\}$.

It has been found that the true value of the central tendency of annual maximum temperature at Guwahati is 7.44 Degree Celsius (Chakrabarty, 2015). 
The estimated value of the central tendency computed from these observations by the existing statistical method of estimation i.e. by applying the formula given by equation (3.3) has been found to be 7.385714286 Degree Celsius.

Thus the estimate of the central tendency suffers from an amount - 0.054285714 Degree Celsius of error.

This can be obtained by equation (3.3) from the amounts of errors involved in the observations as shown in the following table Table-4.4:

\section{Table-4.4}

Error associated to Observed Value of Annual Minimum of Ambient Air Temperature (in Degree Celsius) at Guwahati occurred during Temperature Periodic Year (TPY)

\begin{tabular}{|c|c|c|c|c|c|}
\hline $\begin{array}{l}\text { TPY } \\
\text { No }\end{array}$ & $\begin{array}{l}\text { Observed } \\
\text { Value }\end{array}$ & $\begin{array}{l}\text { Amount of Error Involved } \\
=\text { Observed Value }-37.25\end{array}$ & $\begin{array}{l}\text { TPY } \\
\text { No }\end{array}$ & $\begin{array}{l}\text { Observed } \\
\text { Value }\end{array}$ & $\begin{aligned} & \text { Amount of Error Involved } \\
= & \text { Observed Value }-37.25\end{aligned}$ \\
\hline 1 & 6.6 & -0.84 & 23 & 7.4 & -0.04 \\
\hline 2 & 6.6 & -0.84 & 24 & 5.9 & -1.54 \\
\hline 3 & 5.9 & -1.54 & 25 & 8.4 & 0.96 \\
\hline 4 & 8.2 & 0.76 & 26 & 7.8 & 0.36 \\
\hline 5 & 5.0 & -2.44 & 27 & 7.5 & 0.06 \\
\hline 6 & 6.3 & -1.14 & 28 & 9.4 & 1.96 \\
\hline 7 & 7.4 & -0.04 & 29 & 8.3 & 0.86 \\
\hline 8 & 6.6 & -0.84 & 30 & 8.9 & 1.46 \\
\hline 9 & 6.2 & -1.24 & 31 & 8.6 & 1.16 \\
\hline 10 & 7.3 & -0.14 & 32 & 8.0 & 0.56 \\
\hline 11 & 6.2 & -1.24 & 33 & 7.9 & 0.46 \\
\hline 12 & 6.4 & -1.04 & 34 & 6.7 & -0.74 \\
\hline 13 & 7.5 & 0.06 & 35 & 9.6 & 2.16 \\
\hline 14 & 8.3 & 0.86 & 36 & 6.4 & -1.04 \\
\hline 15 & 4.9 & -2.54 & 37 & 7.8 & 0.36 \\
\hline 16 & 6.1 & -1.34 & 38 & 9.9 & 2.46 \\
\hline 17 & 7.8 & 0.36 & 39 & 8.6 & 1.16 \\
\hline 18 & 8.6 & 1.16 & 40 & 7.0 & -0.44 \\
\hline 19 & 7.7 & 0.26 & 41 & 6.4 & -1.04 \\
\hline 20 & 9.2 & 1.76 & 42 & 5.6 & -1.84 \\
\hline 21 & 6.7 & -0.74 & 43 & & \\
\hline 22 & 8.6 & 1.16 & 44 & & \\
\hline
\end{tabular}

\section{Conclusion}

In this study, error has been determined in the case of Model-1 only. Analysis of error is required to be attempted for each of the other situations, where associations of errors have been identified, discussed in this paper. 
The situation discussed here corresponds to theoretically known relationships between two variables. There is necessity for studying the associations of errors in the situations where more than two variables are related by known theoretical relationships.

There is also necessity for studying the associations of errors in the situations where two and /or more variables are related by unknown theoretical relationships.

It is yet to make study on many useful theoretical models. Some important theoretical models have been outlined below:

\section{Situation-A ( $Y$ theoretically depends upon only one variable $X$ )}

The variable $Y$ theoretically depends upon the variable $X$ obeying the following theoretical models:

\section{A-1:}

$$
Y=a_{0}+a_{1} X+a_{2} X^{2}+
$$$$
+a_{p} X^{p}
$$

where $a_{0}, a_{1}, a_{2}$ $+a_{p}$ are parameters.

A-2:

$$
Y=\mu+\lambda X^{-1}
$$

where $\mu$ and $\lambda$ are parameters.

$$
Y=f\left(X: \mu_{1}, \mu_{2}, \ldots \ldots, \mu_{k}\right)
$$

where $\mu_{1}, \mu_{2}, \ldots \ldots \ldots, \mu_{k}$ are parameters and $f\left(X: \mu_{1}, \mu_{2}, \ldots \ldots, \mu_{k}\right)$ is

some function of $X$.

$$
\text { A- 4: } \quad Y=A \exp \left\{g\left(X: \mu_{1}, \mu_{2}, \ldots \ldots \ldots, \mu_{k}\right)\right\}
$$

where $\mu_{1}, \mu_{2}, \ldots \ldots \ldots, \mu_{k}$ are parameters and $g\left(X: \mu_{1}, \mu_{2}, \ldots \ldots, \mu_{k}\right)$

is some function of $X$.

A-5:

$$
h(X, Y)=\mu
$$

where $\mu$ is a parameters and $h(X, Y)$ is some function of two variables $X$ and $Y$.

\section{Situation-B ( $Y$ theoretically depends upon more than one variable $X$ )}

In some situations, one variable may theoretically depend upon more than two variables.

Suppose, the variable $Y$ depends upon the variables $X_{1}, X_{2}, \ldots \ldots \ldots ., X_{k}$ and

$$
\begin{gathered}
Y_{1}, Y_{2}, \ldots \ldots \ldots \ldots, Y_{n} \\
X_{11}, X_{12}, \ldots \ldots \ldots \ldots, X_{1 n} \\
X_{21}, X_{22}, \ldots \ldots \ldots \ldots, X_{2 n}
\end{gathered}
$$




$$
X_{p 1}, X_{p 2}, \ldots \ldots \ldots \ldots, X_{p n}
$$

are observation on the variables

$$
Y, X_{1}, X_{2}, \ldots \ldots \ldots \ldots, X_{k}
$$

respectively.

The variables

$$
Y, X_{1}, X_{2}, \ldots \ldots \ldots \ldots, X_{k}
$$

are connected by the following theoretical models:

B-1: $f\left(X_{1}, X_{2}, \ldots \ldots \ldots, X_{n}\right)=\mu$

where $\mu$ is the parameter.

B-2: $\quad Y=f\left(X_{i}: \mu_{1}, \mu_{2}, \ldots \ldots \ldots, \mu_{k}\right)$

where $\mu_{1}, \mu_{2}, \ldots \ldots \ldots, \mu_{k}$ are the parameters.

B-3: $\quad Y=A \cdot \exp \left\{f\left(X_{1}, X_{2}, \ldots \ldots \ldots, X_{n}: \mu_{1}, \mu_{2}, \ldots \ldots \ldots, \mu_{k}\right)\right\}$

where $A, \mu_{1}, \mu_{2}, \ldots \ldots \ldots, \mu_{k}$ are the parameters.

B-4: $\quad f\left(X_{1}, X_{2}, \ldots \ldots ., X_{n}\right)=\mu$

where $\mu$ is the parameter.

B-5: $\quad f\left(Y, X_{1}, X_{2}, \ldots \ldots \ldots \ldots, X_{k}\right)=\mu$

where $\mu$ is the parameter.

Thus one problem for further research is to search for the appropriate models, corresponding to these theoretical models, which are to be satisfied by the corresponding observed data containing error and to find out formula for error involved in the estimate of parameter in each case.

\section{Reference}

Aldrich John, “Fisher's Inverse Probability of 1930 ”, International Statistical Review, Vol. 68, pp. 155 - 172, 2000.

Anders Hald, " On the History of Maximum Likelihood in Relation to Inverse Probability and Least Squares", Statistical Science, Vol. 14, pp. 214 - 222, 1999.

Barnard G. A., "Statistical Inference”, Journal of the Royal Statistical Society, Series B, Vol. 11, pp. 115 149, 1949.

Birnbaum Allan, " On the Foundations of Statistical Inference" Journal of the American Statistical Association, Vol. 57, pp. $269-306,1962$. 
Chakrabarty D. "Analysis of Errors Associated to Observations of Measurement Type ", International Journal Electronics and Applied Research (ISSN: 2395-0064), 1(1), 15 - 28, 2014, also available in http://eses.co.in//ESESJuornal.

Chakrabarty D. "Observation Composed of a Parameter and Chance Error: An Analytical Method of Determining the Parameter", International Journal of Electronics and Applied Research, 1(2), (ISSN : 2395 0064), 20 - 38, 2014, also available in http://eses.co.in//ESESJuornal .

Chakrabarty D. " Observation Composed of a Parameter and Chance Error: Determination of the Parameter as Stable Range ", International Journal Electronics and Applied Research (ISSN: 2395-0064), 1(1), 35 - 47, 2015, also available in http://eses.co.in//ESESJuornal.

Chakrabarty D. "Central Tendency of Annual Extremum of Ambient Air Temperature at Guwahati”, Journal of Chemical, Biological and Physical Sciences (E- ISSN: 2249 -1929), Section C, 5(3), 2863 - 2877, 2015, also available in $\underline{w w w . j c b s c .0 r g}$.

Chakrabarty D., "Observation Consisting of Parameter and Error: Determination of Parameter ", Proceedings of the World Congress on Engineering 2015, (WCE 2015, July 1 - 3, 2015, London, U.K.), ISBN: 978-98814047-0-1, ISSN: 2078-0958 (Print); ISSN: 2078-0966 (Online), Vol. II, 680 - 684, 2015.

Chakrabarty D., "Central Tendency of Annual Extremum of Ambient Air Temperature at Guwahati Based on Midrange and Median", J. Chem. Bio. Phy. Sci. (E- ISSN : 2249 - 1929), Sec. D, 5(3), 3193 - 3204, 2015, online available at: $\underline{w w w . j c b s c . o r g}$.

Ivory, " On the Method of Least Squares ”, Phil. Mag., vol. LXV, pp. 3 - 10, 1825.

Kendall M. G. and Stuart A., "Advanced Theory of Statistics ", Vol. 1 \& 2, $4^{\text {th }}$ Edition, New York, Hafner Press, 1977.

Lehmann Erich L. \& Casella George, “ Theory of Point Estimation”, 2nd ed. Springer. ISBN 0 - 387 - 98502 6, 1998.

Lucien Le Cam, “ Maximum likelihood - An introduction ”, ISI Review, Vol. 58, no. 2, pp. 153 -171, 1990.

Walker Helen M. and Lev J., "Statistical Inference”, Oxford \& IBH Publishing Company, 1965. 